\title{
Treinamento físico durante a recuperação nutricional não afeta o metabolismo muscular da glicose de ratos
}

\author{
Vanessa Santhiago ${ }^{1}$, Adelino Sanchez Ramos da Silva ${ }^{1}$, \\ Claudio Alexandre Gobatto ${ }^{1}$ e Maria Alice Rostom de Mello $^{1}$
}

\section{RESUMO}

O presente estudo visou avaliar a ingestão alimentar, ganho de peso e metabolismo muscular da glicose em ratos submetidos ao treinamento aeróbio durante recuperação de desnutrição protéica. Para isso, 60 ratos da linhagem Wistar, machos, foram separados nos grupos normoprotéico (NP) e hipoprotéico (HP), de acordo com a dieta NP ( $17 \%$ de proteína) ou HP ( $6 \%$ de proteína), respectivamente, recebida do desmame ( 21 dias) aos 90 dias de idade. Todos os animais passaram então, a receber a dieta NP e foram submetidos (treinado - TRE) ou não (sedentário - SED) ao treinamento físico, que consistiu de corrida em esteira rolante, $25 \mathrm{~m} / \mathrm{min}$, 50 minutos ao dia, cinco dias na semana, durante 30 dias, compondo os grupos NP-SED, NP-TRE, HP/NP-SED e HP/ NP-TRE. Foi avaliado o metabolismo da glicose em fatias de músculo sóleo incubado em presença de insulina (100 $\mu \mathrm{U} / \mathrm{L})$ e glicose $\left(5,5 \mathrm{mM}\right.$, contendo $\left[\mathrm{C}^{14}\right]$ glicose e $\left[\mathrm{H}^{3}\right]$ 2-deoxiglicose). A ingestão alimentar diária ( $\mathrm{g} / 100 \mathrm{~g}$ de peso corporal) do grupo HP/NP-TRE $(24,39 \pm 4,07)$ foi maior do que o grupo HP/NP-SED $(21,62 \pm 4,69)$. O ganho de peso $(\mathrm{g})$ foi semelhante nos grupos HP/NP-TRE $(203,80$ $\pm 34,03)$ e HP/NP-SED $(214,43 \pm 30,54)$. Não houve diferença entre estes dois grupos quanto aos parâmetros: captação de glicose, oxidação de glicose e síntese de glicogênio pelo músculo sóleo. Desse modo, pudemos concluir que o treinamento aeróbio não teve impacto sobre a recuperação nutricional, visto que não houve diferenças metabólicas ou somáticas entre animais recuperados em presença ou ausência do treinamento.

\section{ABSTRACT \\ Physical training during nutritional recovery does not affect the muscular glucose metabolism in rats}

This study had the main aim to assess the food intake, the weight gain, and the muscular glucose metabolism in rats submitted to aerobic training while recovering of protean malnutrition. For this, 60 male Wistar rats were separated in two groups: normoprotean (NP) and hypoprotean (HP), according to the diet: NP (17\% protein), or HP (6\% protein), respectively, which was received after the ablactation (21 days) on their $90^{\text {th }}$ day of life. Then, very animal received the NP diet, and they were submitted or not (trained TRA; sedentary - SED) to physical training that consisted in running on a treadmill for $25 \mathrm{~m} / \mathrm{min}$., $50 \mathrm{~min} /$ day for 5 days a week for 30 days, compounding the NP-SED, NP-TRA, HP/NP-SED, and HP/ NP-TRA groups. The glucose metabolism was assessed in slices of the soleum muscle incubated in the presence of insulin (100 $\mu \mathrm{U} / \mathrm{L}$ ), and glucose (5.5 mM containing glucose [C $\left.{ }^{14}\right]$, and 2-deoxyglycose $\left[\mathrm{H}^{3}\right]$ ). The daily food intake (g/100 $\mathrm{g}$ of the body weight) for the HP/NP-TRA group (24.39 \pm 4.07$)$ was larger than the HP/ NP-SED group (21.62 \pm 4.69$)$. The weight gain $(g)$ was similar in

1. Universidade Estadual Paulista "J úlio de Mesquita Filho", situada na Av. 24A, 1.515, Bela Vista - 13506-900 - Rio Claro, SP.

Recebido em 30/6/05. Versão final recebida em 3/10/05. Aceito em 4/11/05.

Endereço para correspondência: Vanessa Santhiago, Av. J osé Ariano Rodrigues, 112, apto. 32, J ardim Ariano - 16400-400 - Lins, SP. E-mail: vanessas@rc.unesp.br

\author{
Palavras-chave: Treinamento. Desnutrição protéica. Recuperação nutricional. \\ Keywords: $\quad$ Training. Protean malnutrition. Nutritional recovery. \\ Palabras-clave: Entrenamiento. Desnutrición portéica. Recuperación nutritiva.
}

both groups HP/NP-TRA (203.80 \pm 34.03$)$ and HP/NP-SED (214.43 \pm 30.54). There was no difference between both groups in relation to the following parameters: glucose uptake and oxidation, and glycogen synthesis by the soleum muscle. Thus, it can be concluded that the aerobic training did not have any impact on the nutritional recovery, as there was no metabolic or somatic differences among recovered animals in the presence or absence of the training.

\section{RESUMEN}

\section{La educación física durante la recuperación nutritiva no afec- ta el metabolismo muscular de la glucosa en ratones}

El estudio presente buscó evaluar la ingestión alimentaría, y la ganancia de peso y el metabolismo muscular de la glucosa en ratones sometidos al entrenamiento aeróbico durante la recuperación protéica de la desnutrición. Para esto, 60 ratones del linaje Wistar, los varones estaban separados en grupos: normoprotéico (NP) e hipoprotéico (HP), de acuerdo con la dieta NP (17\% de proteína) o HP (6\% de proteína), respectivamente, recibida del desmame (21 días) a los 90 días de edad. Todos los animales pasaron entonces, para recibir la dieta NP y algunos fueron sometidos (entrenado - TRE) o ningún (sedentario - SED) educación física que consistió en carrera de cinta rodante, 25m/min., 50 minutos por día, 5 días en la semana, durante 30 días, que componen los grupos NP-SED, NP-TRE, HP/NP-SED y HP/NP-TRE. El metabolismo de la glucosa se evaluó en las muestras de músculo sóleo incubadas en presencia de insulina $(100 \mu \mathrm{U} / \mathrm{L})$ y glucosa $(5,5 \mathrm{mM}$, conteniendo $\left[\mathrm{C}^{14}\right]$ la glucosa y $\left[\mathrm{H}^{3}\right]$ 2-deoxiglicose). Mientras que la ingestión diariamente alimentaría (el g/100g de peso corpóreo) del grupo HP/NP-TRE de grupo $(24,39 \pm 4,07)$ era más grande que del grupo HP/NP-SED de grupo $(21,62 \pm 4,69)$. Las ganancias de peso (g) fueron similares en los grupos HP/NP-TRE $(203,80 \pm 34,03)$ y HP/NP-SED $(214,43 \pm 30,54)$. No había diferencia entre estos dos grupos en cuanto a los parámetros: la recepción de glucosa, oxidación de glucosa y síntesis del glucógeno para el músculo sóleo. De esta manera, nosotros podríamos concluir que los entrenamientos aeróbicos no tenían el impacto sobre la recuperación nutritiva, porque no había diferencias metabólicas o somáticas entre animales recuperados en presencia o ausencia del entrenamiento.

\section{INTRODUÇÃO}

Apesar de diversos estudos demonstrarem que é possível produzir alimentos suficientes para toda a população mundial, 826 milhões de pessoas continuam sofrendo de desnutrição crônica. A cada ano, 36 milhões de pessoas morrem em conseqüência da fome no mundo(1).

A desnutrição protéica implica em diversas alterações metabólicas. Vários estudos com crianças desnutridas indicam diminuição dos níveis glicêmicos e baixo conteúdo de glicogênio hepáti- 
$\mathrm{CO}^{(2)}$. O restabelecimento das variáveis metabólicas com a recuperação nutricional é lento. De acordo com a literatura, o exercício físico pode trazer benefícios ao processo de recuperação nutricional. Ao serem comparados os ritmos de crescimento de crianças que se recuperavam de desnutrição em hospitais, verificou-se que crianças moderadamente ativas, que participavam de atividades envolvendo baixo gasto energético, apresentavam mais massa magra e cresciam mais rapidamente que aquelas que realizavam o procedimento padrão dos hospitais ${ }^{(3)}$. Além disso, o treinamento físico, sabidamente leva ao aumento de reservas teciduais de glicogênio(4), o que pode auxiliar no restabelecimento do metabolismo glicídico desnutrido.

Por razões óbvias, grande número de pesquisas envolvendo a desnutrição protéica tem sido conduzido em animais de laboratório, especialmente ratos, uma vez que estes apresentam similaridades metabólicas com seres humanos. Um modelo experimental de desnutrição crônica precoce bastante aceito e que se assemelha em muitos aspectos ao que acontece na população infantil brasileira é o da restrição protéica alimentar(5). Contudo, a despeito da importância do problema, existem poucos estudos na literatura envolvendo fatores bioquímicos de ratos desnutridos associados ao exercício físico crônico.

Gobatto et al.(4) estudaram os aspectos metabólicos de ratos em três etapas: restrição protéica, por 60 dias, seguida de recuperação nutricional de seis semanas e subseqüente treinamento físico, que foi constituído de sessões de natação de uma hora por dia, cinco dias por semana, durante sete semanas. Os autores constataram que os animais que foram tratados com dieta hipoprotéica apresentaram desempenho semelhante ao dos ratos que não foram submetidos à desnutrição; e os estoques teciduais de glicogênio, juntamente com a resposta do lactato sanguíneo ao exercício agudo, bem como as concentrações séricas de substratos, apresentaram valores semelhantes entre os grupos treinados, independentemente do estado nutricional anterior.

Galdino et al.(2) avaliaram os efeitos da desnutrição protéica intra-uterina e pós-natal, até a idade adulta (90 dias), nas adaptações do metabolismo muscular da glicose ao treinamento de natação. Os autores verificaram um aumento da captação de glicose e do teor de glicogênio muscular nos animais treinados. A síntese de glicogênio esteve reduzida nos animais desnutridos sedentários, mas foi restaurada nos exercitados. Os autores concluíram que a desnutrição protéica prolongada não prejudicou as adaptações metabólicas ao treinamento.

Papoti et al.(6) avaliaram a cinética de lactato sanguíneo de ratos adultos recuperados de desnutrição protéica, durante exercício de natação, pela determinação da máxima fase estável de lactato. Para isso, cada animal realizou quatro testes de natação por 20 minutos suportando sobrecargas entre 4,5 e 7,5\% do peso corporal. A máxima fase estável de lactato foi obtida na carga de 5,5\% do peso corporal em concentração sanguínea de 5,5 e 4,7 $\mathrm{mmol} / \mathrm{l}$, respectivamente para ratos controles e recuperados de desnutrição. Tais resultados levaram os autores à conclusão de que a desnutrição precoce pode afetar a cinética de lactato durante o exercício.

Visto que existem relatos sugerindo que o treinamento físico possa ser benéfico ao processo de recuperação nutricional, o presente estudo foi delineado para avaliar o metabolismo glicídico muscular de ratos submetidos à restrição protéica alimentar precoce e posterior recuperação nutricional associada ou não ao treinamento físico.

\section{MÉTODOS}

\section{Animais e dietas}

A amostra experimental foi composta por 60 ratos machos da linhagem Wistar, que iniciaram o experimento com 21 dias de ida- de. Os ratos foram mantidos em gaiolas de polietileno individuais sob condições controladas de ciclo claro-escuro (12/12h), com livre acesso à água e ração (dietas normoprotéica e hipoprotéica) manipulada no Laboratório de Biodinâmica da Universidade Estadual Paulista "J úlio de Mesquita Filho", Campus de Rio Claro. A composição das dietas encontra-se descrita na tabela 1. Todos os experimentos com animais foram realizados de acordo com o European Convenction for Protection of Vertebrate Annimals Used for Experimental and Other Scientific Purposes ${ }^{(7)}$.

\begin{tabular}{lcc}
\hline & $\begin{array}{c}\text { TABELA 1 } \\
\text { Composição das dietas }\end{array}$ \\
\hline \multicolumn{1}{c}{ Componentes (g/ kg) } & $\begin{array}{c}\text { Normoprotéica* } \\
\text { (17\% de proteína) }\end{array}$ & $\begin{array}{c}\text { Hipoprotéica** } \\
\text { (6\% de proteína) }\end{array}$ \\
Caseína (84\% de proteína) & 202 & 71,5 \\
Amido de milho & 397 & 480 \\
Dextrina de milho & 130,5 & 159 \\
Sacarose & 100 & 121 \\
L-cistina & 3 & 1 \\
Óleo de soja & 70 & 70 \\
Mistura de sais (AIN 93-G) & 35 & 35 \\
Mistura de vitaminas (AIN 93-G) & 10 & 10 \\
Microcelulose & 50 & 50 \\
Cloridrato de colina & 2,5 & 2,5
\end{tabular}

* Dieta para fase de crescimento, gravidez e lactação de roedores - AIN - 93G(33). ** Dieta para indução de quadro de desnutrição(33).

\section{Delineamento e grupos experimentais}

O estudo foi delineado em duas etapas. Na primeira, os animais foram separados em dois grupos, de acordo com a dieta; normoprotéico - alimentados com a dieta normoprotéica do desmame aos 60 dias de idade, e hipoprotéico - alimentados com a dieta hipoprotéica do desmame aos 60 dias de idade.

Em seguida, iniciou-se a segunda etapa, quando os animais de ambos os grupos passaram a receber ração normoprotéica, compondo quatro grupos de acordo com o estado nutricional e a presença ou ausência de treinamento físico, sendo Normoprotéico Sedentário (NP-SED), Normoprotéico Treinado (NP-TRE), Hipo/Normoprotéico Sedentário (HP/NP-SED) e Hipo/Normoprotéico Treinado (HP/NP-TRE) o. No caso dos animais inicialmente submetidos à desnutrição protéica, a alimentação com a ração normoprotéica visou a recuperação nutricional.

Durante todo o experimento, os animais tiveram ganho de peso e quantidade de alimento ingerido registrados uma vez por semana. Foram também medidos o comprimento focinho-ânus aos finais da primeira e da segunda etapa.

\section{Protocolo de treinamento físico}

Antes do início do período de treinamento, os ratos designados NP-TRE e HP/NP-TRE realizaram 10 dias de adaptação ao ergômetro (esteira rolante), onde correram cinco minutos à velocidade de $10 \mathrm{~m} / \mathrm{min}$ durante três dias; seis minutos à velocidade de $15 \mathrm{~m} / \mathrm{min}$ durante três dias; e sete minutos à velocidade de $20 \mathrm{~m} / \mathrm{min}$ durante três dias.

Após a adaptação, iniciou-se o período de treinamento, que foi composto por sessões diárias de corrida, cinco dias por semana, durante quatro semanas. O tempo de exercício e a velocidade da esteira foram incrementados gradualmente até que os animais corressem por 50 minutos à velocidade de $25 \mathrm{~m} / \mathrm{min}$. Esse protocolo de treinamento foi escolhido por tratar-se de exercício aeróbio para ratos ${ }^{(8)}$.

\section{Teste de esforço}

Antes e após o período de treinamento, os grupos NP-TRE e HP/NP-TRE foram submetidos a uma sessão de exercício de corrida na esteira à velocidade constante de $25 \mathrm{~m} / \mathrm{min}$ durante $20 \mathrm{mi}$ nutos. Em repouso e a cada cinco minutos de corrida, os ratos 
foram brevemente retirados da esteira rolante para a coleta de $25 \mu l$ de sangue da cauda para a determinação de lactato. As amostras de sangue foram imediatamente transferidas para tubos Eppendorf contendo 50ul de solução hemolisante (fluoreto de sódio 1\%), para posterior análise sanguínea em analisador eletroquímico (lactímetro YSI 1500 Sport).

\section{Sacrifício dos animais e obtenção do material biológico}

Decorridos 48 horas do último teste de esforço, os animais foram sacrificados em repouso, através da decapitação. O sangue do tronco foi recolhido em tubos de vidro onde foi separado o soro para determinações de glicose, ácidos graxos livres (AGL), albumina e proteínas totais. Após a coleta de sangue, através de laparotomia mediana, foi retirada uma porção do fígado para posterior determinação de glicogênio e da gordura. Foram ainda retiradas das patas traseiras os dois músculos sóleos, para procedimentos de incubação, visando avaliação do metabolismo glicídico. Após 48 horas do primeiro teste de esforço, foram coletadas amostras de sangue a partir de corte na extremidade distal da cauda dos animais, para a determinação das concentrações de glicose, AGL, proteínas totais e albumina(9).

\section{Incubação do músculo sóleo}

As fatias de músculo sóleo foram colocadas em frascos de cintilação com capacidade de $20 \mathrm{~mL}$ siliconizados, contendo $1,5 \mathrm{~mL}$ de tampão Krebs-Ringer bicarbonato. Os frascos foram fechados com tampas de borracha, selados com anel plástico e submetidos a 30 minutos de pré-incubação sob agitação em banho tipo Dubinoff a 60rpm e contínuo gaseamento com $\mathrm{O}_{2} / \mathrm{CO}_{2}(95 \% / 5 \%)$. Após esse período, as fatias do músculo foram transferidas para novos frascos de cintilação (frasco externo), em cujo interior foram instalados pequenos tubos em forma de concha (frasco interno), com uma haste reta de aproximadamente $3 \mathrm{~cm}$ de comprimento que se insere nas tampas de borracha do frasco externo. Cada frasco externo continha $1,5 \mathrm{~mL}$ de tampão Krebs-Ringer e cada frasco interno, 700 $\mathrm{LL}$ de hiamina 10x. Após 60 minutos de incubação nesse sistema, com gaseamento durante os 15 primeiros minutos, foram adicionados $100 \mu \mathrm{L}$ de ácido tricloroacético (TCA) $25 \%$ ao frasco externo visando a liberação de $\mathrm{CO}_{2}$. A preparação foi mantida por mais três horas no sistema. Decorrido esse tempo, $200 \mu \mathrm{L}$ do líquido contido no frasco intemo foram retirados para a determinação do $\mathrm{CO}_{2}$ produzido. $\mathrm{O}$ meio de incubação acidificado contido no frasco externo foi armazenado para a determinação do lactato e a fatia de músculo imediatamente digerida em $0,5 \mathrm{~mL}$ de $\mathrm{KOH}^{(10)}$ para a dosagem do glicogênio muscular(11). A temperatura na pré-incubação e incubação foi de $37^{\circ}$.

O tampão Krebs-Ringer, base dos meios de pré-incubação e incubação, consistiu de $\mathrm{NaCl} 6 \%$, HEPES 6,64mM, $\mathrm{KCl} 0,032 \%$, $\mathrm{CaCl}_{2} 1,12 \mathrm{nM}, \mathrm{KH}_{2} \mathrm{PO}_{4}$ 0,015\%, $\mathrm{NaHCO}_{3}$ 0,19\%, $\mathrm{MgSO}_{4}$ 0,03\%. A solução assim preparada foi gaseada durante 30 minutos em $\mathrm{O}_{2} /$ $\mathrm{CO}_{2}(95 \% / 5 \%)$ e o pH ajustado a 7,4. A esta solução foram adicionados 20 volumes de albumina sérica bovina livre de gordura. Ao meio de pré-incubação foi adicionado piruvato de sódio para a concentração de $5 \mathrm{mM}$. Ao meio de incubação, foi adicionado glicose $(5,5 \mathrm{mM})$ contendo $\left[\mathrm{U}_{{ }_{14}} \mathrm{C}\right]$ glicose $(0,25 \mu \mathrm{Ci} / \mathrm{mL}),\left[{ }^{3} \mathrm{H}\right] 2$-deoxiglicose $(2-D G=0,5 \mu \mathrm{Ci} / \mathrm{mL})$ e insulina $(100 \mu \mathrm{UL} / \mathrm{mL})$. Feitas as adições, o $\mathrm{pH}$ foi ajustado a 7,4 e o meio transferido para os frascos que foram selados e equilibrado no banho a $37^{\circ} \mathrm{C}$ sob gaseamento $\mathrm{O}_{2} /$ $\mathrm{CO}_{2}(95 \% / 5 \%)$ durante pelo menos 15 minutos. Fatias do mesmo músculo com peso semelhante àquelas incubadas foram utilizadas para a determinação da concentração do controle de glicogênio. Foram avaliadas captação de glicose, utilizando a 2-DG como marcador, e incorporação do ${ }^{14} \mathrm{C}$ a glicogênio (síntese), medindose a radioatividade do ${ }^{14} \mathrm{C}$ da glicose e ${ }^{3} \mathrm{H}$ da 2-DG contidas, respectivamente, no precipitado e na fase alcoólica da extração do glicogênio, através de contador de partículas beta. O lactato liberado no meio de incubação foi determinado por separação de me- tabólitos em coluna de troca iônica (Dowex-2, Sigma), o que representa um índice do transporte de glicose nessas condições. Além do lactato radioativo foi também determinado o total de lactato no meio de incubação por método enzimático. Para a estimativa da glicose oxidativa (produção de $\mathrm{CO}_{2}$ ), foi determinada a radioatividade do ${ }^{14} \mathrm{C}$ presente no líquido (hiamina) coletado no frasco interno do sistema de incubação.

\section{Determinações bioquímicas}

A glicose sérica foi determinada pelo método enzimático da glicose-oxidase, as proteínas totais, pelo reagente biureto, a albumina pelo verde de bromocresol, e os AGL pelo dietilcarbamato. $O$ glicogênio tecidual foi extraído segundo método de Sjorgren et al.(10) e a coloração do precipitado foi realizada empregando fenol, segundo Dubois et al.(11).

\section{Análise estatística}

Os procedimentos estatísticos incluíram teste $t$ de Student não pareado ou ANOVA de duas entradas, seguido de teste post-hoc de Bonferroni quando necessário. Em todos os casos adotou-se um nível de significância de $p<0,05$.

\section{RESULTADOS}

Na primeira etapa do estudo, os animais que receberam a dieta hipoprotéica tiveram ganho de peso significativamente menor e ingestão alimentar significativamente maior, quando comparados com os normoprotéicos, após oito semanas de tratamento com as dietas (tabela 2). Os animais mantidos com a dieta hipoprotéica apresentaram ainda concentrações significativamente maiores de AGL séricos e significativamente menores de proteínas totais, albumina e glicose, em relação ao grupo normoprotéico (tabela 2).

Na segunda etapa do estudo, os grupos treinados (NP-TRE e HP/NP-TRE) mostraram ingestão alimentar diária superior aos respectivos grupos sedentários (NP-SED e HP/NP-SED) (tabela 2). Com relação ao ganho de peso, os grupos recuperados treinados (HP) NP-TRE) tiveram ganho significativamente menor, quando comparados com os demais grupos (HP/NP-SED, NP-TRE e NP-SED).

\section{TABELA 2}

Ganho de peso (g) e ingestão alimentar diária (g/ $100 \mathrm{~g}$ de peso corporal), teores séricos de ácidos graxos livres (AGL em $\mu \mathrm{Eq} / \mathrm{L}$ ), proteínas totais $(\mathrm{g} / \mathrm{dL}$ ), albumina ( $\mathrm{g} / \mathrm{dL}$ ) e glicose $(\mathrm{mg} / \mathrm{dL}$ ) ao final da primeira etapa do estudo

\begin{tabular}{lcc} 
& Controle & Desnutrido \\
Ganho de peso & $232,18 \pm 21,11$ & $76,16 \pm 21,01^{*}$ \\
Ingestão alimentar & $17,4 \pm 4,11$ & $22,1 \pm 4,09^{*}$ \\
AGL & $260,0 \pm 12,0$ & $322,0 \pm 45,0^{*}$ \\
Proteínas totais & $6,5 \pm 0,2$ & $5,5 \pm 0,1^{*}$ \\
Albumina & $5,9 \pm 0,1$ & $4,7 \pm 0,1^{*}$ \\
Glicose & $122,1 \pm 5,1$ & $100,0 \pm 4,2^{*}$ \\
\hline
\end{tabular}

Resultados expressos como média e desvio-padrão de 20 animais por grupo.

* Diferença significativa ( $p<0,05$, teste $t$ ) em relação ao controle.

A figura 1 mostra os valores de lactato sanguíneo dos grupos treinados (NP-TRE e HP/NP-TRE) nos testes de esforço realizados antes (painel superior) e após (painel inferior) o treinamento físico. No teste realizado antes do treinamento, o lactato sanguíneo estabilizou-se a partir de cinco minutos de exercício no grupo recuperado (HP/NP-TRE) e após 10 minutos no grupo controle (NPTRE) em valores semelhantes $(3,72 \pm 1,06$ e 4,60 $\pm 1,44 \mathrm{mmol} / \mathrm{L}$, para NP-TRE e HP/NP-TRE, respectivamente). No teste realizado ao final de quatro semanas de treinamento, o lactato sanguíneo estabilizou-se após cinco minutos de exercício em ambos os grupos, em valores inferiores aos observados no primeiro teste $(2,98$ $\pm 1,02$ e $2,15 \pm 0,97 \mathrm{mmol} / \mathrm{L}$, para HP-TRE e HP/NP-TRE, respectivamente). A redução foi significativa apenas para o grupo recuperado (HP/NP-TRE). 


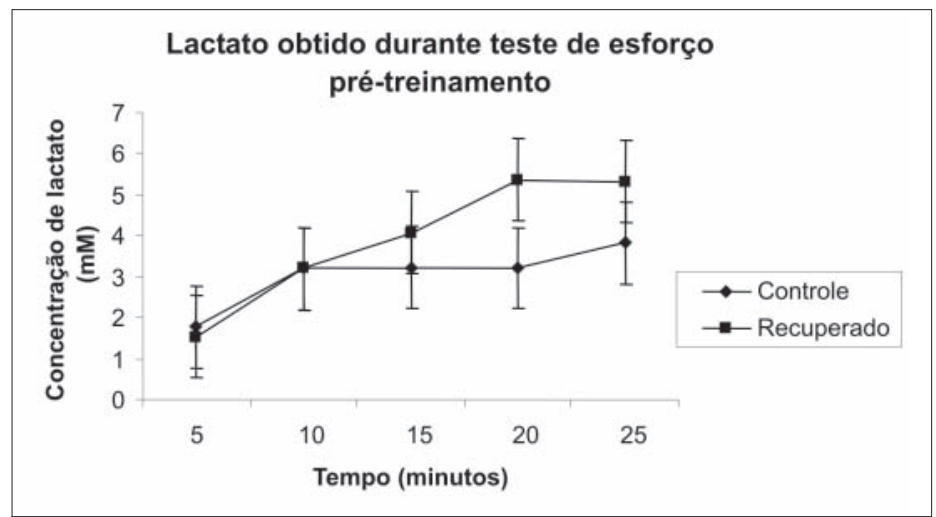

Lactato obtido durante teste de esforço pós-treinamento

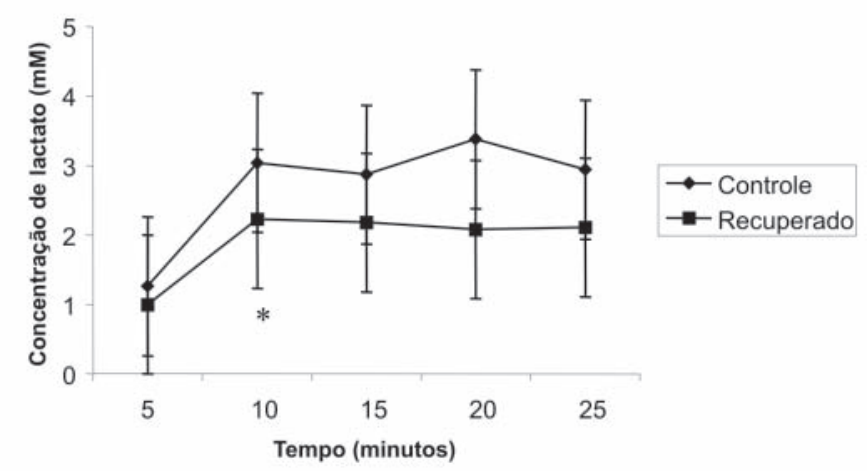

Figura 1 - Lactato sanguíneo dos grupos CT e RT durante os testes de esforço realizados antes (painel superior) e após (painel inferior) o treinamento físico. Antes do treinamento o lactato sanguíneo estabilizou-se após cinco minutos de exercício no grupo recuperado $(3,72 \pm 1,06 \mathrm{mmol} / \mathrm{L})$, e após 10 minutos no grupo controle $(4,60 \pm 1,44 \mathrm{mmol} / \mathrm{L})$. Após o treinamento, o lactato sanguíneo estabilizou-se após cinco minutos de exercício em ambos os grupos (controle 2,98 $\pm 1,02$ e recuperado 2,15 $\pm 0,97 *$ $\mathrm{mmol} / \mathrm{L})$. Como critério de estabilização, considerou-se diferença inferior a 1,0mmol/L entre os grupos. O grupo recuperado apresentou uma diminuição significativa na concentração de lactato após o treinamento em esteira rolante de 30 dias. Resultados expressos como média e desvio padrão de oito amostras teciduais em cada grupo.

* Diferença significativa $p<0,05$, em relação ao exercício realizado antes do treinamento de 30 dias no mesmo grupo.
O grupo controle treinado (NP-TRE) apresentou concentração de glicogênio hepático significativamente maior quando comparado com os demais grupos (NP-SED, HP/NP-SED e NP-TRE). Com relação aos lipídeos hepáticos, não foram constatadas diferenças significativas entre os grupos. O glicogênio muscular apresentou valores significativamente menores nos animais treinados (NP-TRE e HP/NP-TRE) que nos sedentários, (NP-SED e HP/NP-SED) (tabela 3).

Não houve diferença significativa entre os valores de captação de glicose, oxidação de glicose, incorporação (síntese) de glicose em glicogênio pelo músculo sóleo isolado dos ratos (tabela 3).

\section{DISCUSSÃO}

Os resultados referentes ao ganho de peso corporal, ingestão alimentar e comprimento dos ratos na primeira etapa do estudo indicam que a dieta a $6 \%$ de proteína foi eficaz em induzir estado de desnutrição nos animais. Da mesma forma, concentrações sanguíneas de glicose, proteínas totais e albumina baixas e teores séricos de AGL elevados são características comumente observadas em seres humanos desnutridos ${ }^{(12)}$ e modelos animais de desnutrição $0^{(2,13,14)}$.

A redução do ganho de peso corporal em ratos submetidos à restrição protéica é fenômeno amplamente relatado na literatu$\mathrm{ra}^{(15)}$ e tem sido associado a alterações funcionais e morfológicas.

Ratos mantidos com dieta hipoprotéica mostram um quadro semelhante à desnutrição infantil tipo Kwashiorkor, que tem como características básicas: baixo peso, hipoproteinemia, hipoalbuminemia, elevados teores séricos de AGL e esteatose hepática ou fígado gorduroso $0^{(1,2)}$.

Um aspecto importante é que as alterações por nós observadas decorreram da deficiência protéica e não calórica, visto que ambas as dietas foram isocalóricas e os ratos desnutridos por esse modelo apresentaram ingestão alimentar superior em relação ao grupo controle. Vários estudos anteriores de nosso grupo têm mostrado a elevada ingestão alimentar de ratos mantidos com dieta hipoprotéica ${ }^{(4,8,16)}$.

Tal alteração pode ser decorrente, entre outros fatores, de modificações em mediadores como grelina e leptina. A leptina é uma proteína produzida pelo tecido adiposo que desempenha importante papel através do aumento da queima calórica e redução da ingestão alimentar(17-19). J á a grelina é um hormônio gastrointestinal identificado recentemente no estômago de ratos ${ }^{(20)}$. Estudos em modelos animais indicam que a grelina desempenha importante papel na sinalização dos centros hipotalâmicos que regulam a ingestão alimentar e o balanço energéti$\mathrm{co}^{(21-25)}$.

Sabe-se ainda que as concentrações séricas de grelina são influenciadas por mudanças agudas e crônicas no estado nutricional, encontrando-se elevados em estado de anorexia nervosa e reduzidos na obesidade, diferentemente da leptina que se encontra elevada em ratos obesos ${ }^{(24,26-28)}$. Desse modo, serão necessárias avaliações no modelo de desnutrição protéica para se interferir com precisão sobre a contribuição desses mediadores para as alterações na ingestão alimentar observada no presente estudo.

Na segunda etapa do estudo, verificouse que proteínas totais, glicose, albumina e AGL séricos, assim como glicogênio hepático e muscular, e lipídeos 
hepáticos, apresentaram concentrações semelhantes nos animais recuperados aos encontrados nos animais controles. A massa corporal permaneceu reduzida. Estes dados estão de acordo com os resultados previamente encontrados ${ }^{(1,6)}$, e sugerem a recuperação nutricional parcial dos ratos previamente desnutridos.

Captação de glicose, oxidação de glicose e incorporação (síntese) de glicose em glicogênio pelo músculo sóleo, isolado dos ratos no final da segunda fase do estudo, não apresentaram diferenças significativas entre os grupos recuperado e controle, tanto para os animais treinados como para os sedentários, sugerindo que a restrição protéica alimentar precoce não interfere no metabolismo muscular da glicose após recuperação.

Crace et al. ${ }^{(29)}$ relataram um aumento na síntese de glicogênio em ratos com restrição protéica e também uma maior captação de glicose pelo músculo sóleo isolado de ratos submetidos a dieta hipoprotéica em relação aos alimentados com a dieta normoprotéica. Por outro lado, Nolte et al.(30) não encontraram diferença na síntese de glicogênio entre os animais controles e recuperados em proteínas, estudando fatias musculares incubadas na ausência e na presença de AGL.

Os resultados dos testes de esforço mostraram que o protocolo de treinamento por corrida em esteira levou à redução do acúmulo de lactato no sangue durante o exercício, sugerindo melhora do condicionamento aeróbio nesses animais. O treinamento físico normalmente reduz o acúmulo de lactato durante o exercício para a mesma intensidade submáxima de esforço, devido à maior capacidade de remoção dos substratos da circulação(31).

Por outro lado, a redução do lactato sanguíneo durante o exercício nos grupos treinados, em relação ao sedentário, pode dever-se simplesmente à redução das reservas musculares de glicogênio, pois, no presente estudo, os animais submetidos ao treinamento físico, independente do estado nutricional, apresentaram redução das concentrações de glicogênio muscular. Esses resultados contrapõem-se a relatos clássicos da literatura, indicando presença de estoques elevados de glicogênio muscular em seres humanos e animais submetidos ao treinamento físico ${ }^{(32)}$.

Considerando que animais treinados e sedentários mostraram valores semelhantes para captação de glicose e síntese de glicogênio in vitro pelo músculo sóleo isolado, as baixas concentrações de glicogênio muscular dos treinados avaliados em repouso podem ser conseqüência de recuperação incompleta após cada sessão de exercício.

Em resumo, pode-se concluir que, na primeira etapa, a dieta hipoprotéica foi eficiente em induzir o estado de desnutrição protéica nos ratos. Na segunda etapa, houve o retomo dos valores dos parâmetros bioquímicos analisados ao normal.

Com relação ao treinamento, este não teve impacto sobre a recuperação nutricional, visto que não houve diferenças metabólicas ou somáticas entre animais recuperados em presença ou ausência do treinamento. Detectou-se, apenas, aumento da ingestão alimentar nos grupos treinados, sugerindo redução na eficiência alimentar, em função do aumento da demanda energética decorrente do treinamento. Provavelmente, a freqüência da realização do exercício foi inadequada para a observação dos efeitos desejados. Mais estudos estão em andamento em nossos laboratórios visando ampliar o período de treinamento dos animais, bem como, avaliar a adaptação oxidativa do músculo esquelético através de atividades enzimáticas.

Todos os autores declararam não haver qualquer potencial conflito de interesses referente a este artigo.

\section{REFERÊNCIAS}

1. Torun B, Chew F. Protein energy malnutrition. Modem nutrition in healthy and disease. Philadelphia: Lea e Febiger, 1994.
2. Galdino R, Mello MAR, Almeida RL, Almeida CCS. Desnutrição protéico-calórica. In: Dâmaso A, editor. Nutrição e exercício na prevenção de doenças. São Paulo: Medsi, 2001;10:433.

3. Torun B, Viteri FE. Influence or exercise on linear growth. Eur J Clin Nutrition 1994;48(Suppl I):S186-90.

4. Gobatto CA. Alterações metabólicas decorrentes do treinamento físico em ratos previamente desnutridos e recuperados. [Dissertação de Mestrado]. UNICAMP, Campinas, 1993.

5. Gopalan S. Malnutrition: causes, consequences, and solutions. Nutrition 2000; 16:7-8.

6. Papoti M, Almeida PBL, Prada FJ A, Eleno TG, Hermini HA, Gobatto CA, et al Máxima fase estável de lactato durante a natação em ratos recuperados de desnutrição protéica. M otriz, Rio Claro 2003;9:97-103.

7. Concil of Europe. Strasbourg, no. 123, 1985.

8. Manchado FB, Gobatto CA, Contarteze RVL, Papoti M, Mello MAR. Maximal lactate steady state in running rats. J Exerc Physiol online 2005;8:1-8.

9. Nogueira DM. Métodos de bioquímica clínica. São Paulo: Pancast, 1990;468p.

10. Sjorgren B, Nordensklold T, Holmegren H, Wollerstrom J . Beitrag zur kenttnis des lebernnhytmik. Pflugers Archiv fur die Gesamte Physiologie des Menschem und der Tiere 1938;240-7.

11. Dubois B, Gilles KA, Hamilton J K, Rebers PA. Colorometric method for determination of sugar relate substances. Analytical Chemistry 1956;28:350-6.

12. Waterlow J C, Alleyne GAO. Má nutrição protéica em crianças. Evolução dos conhecimentos nos últimos dez anos. São Paulo: L.P.M. Editora, 1974;120p.

13. Lunn PGE, Austin S. Differences in nitrogen metabolism between protein-deficient and energy-deficient rats with similary restricted growth rates. Ann Nutr Metab 1983;27:242-51.

14. Gobatto CA, Sibuya CY, Azevedo J RM, Luciano E, Kokubun E, Mello MAR. Caracterização da intensidade de exercício e do efeito de treinamento físico no modelo de natação de ratos Wistar. M otriz, Rio Claro 2001a; 7:S57-S62.

15. Escriva F, Kergoat M, Bailbé D, Pascual-Leone AM, Portha B. Increased insulin action in the rat after protein malnutrition early in life. Diabetologia 1991;34:559-64.

16. Carneiro EM, Mello MAR, Gobatto CA, Boschero AC. Low protein diet impairs glucose-induced insulin secretion from and 45Ca uptake by pancreatic rats islets. Nutr Biochem 1995;6:314-8.

17. Romero CEM, Zanesco A. O papel dos hormônios leptina e grelina na gênese da obesidade. BrazJ Nutr 2005 (in press)

18. Ahima RS, Osei SY. Leptin signaling. Physiol Behav 2004;81:223-41.

19. Moraes C, Romero CEM, Zanesco A. Serum leptin level in hypertensive middleaged obese women. The Endocrinologist 2005;15:219-21.

20. Kojima M, Hosoda H, Matsuo, H, Kangawa K. Ghrelin: discovery of the natural endogenous ligand for the growth-hormone secretagogue receptor. Trends Endocrinol Metabol 2001;12:118-22.

21. Hosoda H, Kojima M, Matsuo H, Kangawa K. Ghrelin and des-acyl ghrelin: two major forms of rat ghrelin peptide in gastrointestinal tissue. Biochem Biophys Res Commun 2000;279:909-13.

22. Nakazoto O, Murakami N, Date Y, Kojima M, Matsuo H, Kangawa K, et al. A role for ghrelin in the central regulation of feeding. Nature 2001;409:194-8.

23. Broglio F, Benso A, Castiglioni C, Gottero C, Prodam F, Destefanis S, et al. The endocrine response to ghrelin as a function of gender in humans in young and elderly subjects. J Clin Endocrinol Metab 2003;88:1537-42.

24. Rosická M, Krsek M, Matoulek M, J arkovská Z, Marek J , J ustová V, et al. Serum ghrelin levels in obese patients: the relationship to serum leptin levels and soluble leptin receptors levels. Physiol Res 2003;52:61-6.

25. Vendrell J , Broch M, Vilarrasa N, M olina A, Gómez J M, Gutiérrez C, et al. Resistin, adiponectin, ghrelin, leptin, and proinflammatory cytokines: relationship in obesity. Obes Res 2004;12:962-71.

26. Tshop M, Smiley DL, Heiman ML. Ghrelin induces adiposity in rodents. Nature 2000;407:908-13.

27. Ukkola O, Poykoo S. Ghrelin, growth and obesity. Ann Med 2002;34:102-8.

28. Salbe AD, Tshop MH, Delparigi A, Venti C, Tataranni PA. Negative relationship between fasting plasma ghrelin concentrations and ad libitum food intake. J Clin Endocrinol Metab 2004;89:2951-6.

29. Crace CJ , Swenne I, Khon PG, Strain J , Milner ROG. Protein energy malnutrition induces changes in insulin sensitivity. Diabetes Metab 1995;16:484-91.

30. Nolte LA, Galuska D, Martin IK, Zierath J R, Wallberg-Henriksson H. Elevated free fatty acid levels inhibit glucose phosphorylation in slow-twitch rat skeletal muscle. Acta Physiol Scand 1994;151:51-9.

31. Pyne BD, Lee H, Swanwick KM. Monitoring the lactate threshold in world-ranked swimmers. Med Sci Sports Exerc 2001;33:291-7.

32. Gobatto CA, Mello MA, Sibuya CY, Azevedo J R, Santos LA, Kokubun E. Maximal lactate steady state in rats submitted to swimming exercise. Comp Biochem Physiol A Mol Integr Physiol, New York 2001;130:21-7.

33. Reeves PG, Nielsen FH, Fahey J GC. AIN-93 purified diets for laboratory rodents: final reports of the American Institute of Nutrition ad hoc writing committee on the reformulation of the AIN-76A rodents diet. J Nutr 1993;23:1939-51. 